\title{
Epidemiology, Clinical Profile of Snake Bite Cases Treated in theni Medical College Hospital, in South India:
}

\author{
Dr.P.S.Vallidevi ${ }^{1}$,Dr.Syed Bahavudeen Hussaini ${ }^{2}$, \\ ${ }^{1,2}$ Assistant professor ,Department of General Medicine ,Madurai Medical college ,Madurai
}

\begin{abstract}
:
Background: In India approximately 1 person is affected by Snake bite every 10 seconds. 1 person dies of Snake bite every 2 hours. Similarly, Snake bite is a common problem in and around Theni district. All the four main kind of snakes namely Cobra (Najanaja), Common krait (Bangarusceruleans), Saw scaled viper (Echiscarenatus) and Russel viper (Daboiarusselii) are present in this region. Though people are aware of the availability of treatment for snake bites in hospital, still some superstitions prevail in these people. There is also lack of uniformity in treating such cases. This study was done to address these issues.
\end{abstract}

Keywords: Envenomation, Consumption coagulopathy

To study

I. Aim

1.Epidemiology and clinical manifestations of snake bite

\section{Materials And Methods}

This study is a prospective observational study done between April-2016 to September-2016 at Theni GH. All patients who gave history of snake bite, who presented with signs of envenomation and for whom ASV was used were included in this study. As the patient gets admitted all the details as per the proforma (age, occupation, place of bite, clinical examination \& clotting time) are recorded and he is followed up during his stay in the hospital..

\section{Conclusion}

Snake bite is a common life threatening emergency so as the ASV anaphylaxis. Consumption Coagulopathy, neurotoxicity, and cellulitis warrants ASV administration. Progression to renal failure requires dialysis. Early administration of ASV in adequate amounts definitely saves the patient from complication.

\section{Result}

Snake bite is common in rural areas around Theni. Totally 85 patients were studied in our hospital. Among the 85 snake bites 68 patients (80\%) had signs of envenomation.Age groups above 30 are more affected. Male are affected more than female. (Male - 61 Persons 71.7\%) (Female - 24 persons 28.2\%)

Table 1

\begin{tabular}{|l|l|l|l|}
\hline Description & Years & $\begin{array}{l}\text { With } \\
\text { Envenomation }\end{array}$ & $\begin{array}{l}\text { Without } \\
\text { Envenomation }\end{array}$ \\
\hline \multirow{2}{*}{$\begin{array}{l}\text { Age } \\
\text { Distribution }\end{array}$} & $14-30$ & 16 Persons (19\%) & 5 Persons (6\%) \\
\cline { 2 - 4 } & $31-50$ & 26 Persons (30.5\%) & 6 Persons (7\%) \\
\cline { 2 - 4 } & $>50$ & 26 Persons (30.5\%) & 6 Persons (7\%) \\
\hline
\end{tabular}

Males had majority of bites and day time bites in fields are common. Bites in the Lower limb (58 Persons - 68\%) is more than the upper limb (27 Persons - 32\%)

Table 2

\begin{tabular}{|l|l|l|}
\hline Description & Time in hours & No. of persons \\
\hline \multirow{2}{*}{ Time of bite } & $6 \mathrm{am}$ to $6 \mathrm{pm}$ & $46(54 \%)$ \\
\cline { 2 - 3 } & $6 \mathrm{pm}$ to $6 \mathrm{am}$ & $39(45.8 \%)$ \\
\hline
\end{tabular}

Most of the Patients report to hospital between 1 to $6 \mathrm{hrs}$ after snake bite. Earliest reporter is $20 \mathrm{~min}$ and one patient reported at $32 \mathrm{hrs}$. 
Table 3

\begin{tabular}{|l|c|c|}
\hline Description & Time in hours & No. of persons \\
\hline \multirow{3}{*}{$\begin{array}{l}\text { Time delay in } \\
\text { reporting to hospital }\end{array}$} & $0-1$ & $23(27 \%)$ \\
\cline { 2 - 3 } & $1-6$ & $50(58.8 \%)$ \\
\cline { 2 - 3 } & $6-24$ & $10(11.7 \%)$ \\
\cline { 2 - 3 } & $>24$ & $2(2.3 \%)$ \\
\hline
\end{tabular}

64 patients had hemotoxic and 4 had both hemotoxic and neurotoxic manifestation. 48 Persons had local envenomation.17 Persons had no signs of toxicity. One Patient had Hematuria and one Patient had Hemoptysis.Hemotoxic snake bites are common and renal failure in these patients is around $5 \%$. Only 4 patients suffered neurotoxicity and none of them required ventilator support.

Table 4

\begin{tabular}{|l|l|l|}
\hline Description & Type & No. of persons \\
\hline \multirow{4}{*}{ Toxicity } & Hemotoxic & $64(75 \%)$ \\
\cline { 2 - 3 } & Neurotoxic & $4(4.7 \%)$ \\
\cline { 2 - 3 } & Local envenomation & $48(56.5 \%)$ \\
\cline { 2 - 3 } & No toxicity & $17(20 \%)$ \\
\hline
\end{tabular}

Maximum no. of Bites were in the field during the Day time.

Table 5

\begin{tabular}{|l|l|l|}
\hline Description & Place of bite & No. of persons \\
\hline \multirow{3}{*}{ Places } & House & $27(31.7 \%)$ \\
\cline { 2 - 3 } & Field & $50(58.8 \%)$ \\
\cline { 2 - 3 } & others & $8(9.4 \%)$ \\
\hline
\end{tabular}

Maximum ASV used for a patient is 29 vials and minimum ASV used is 5 vials. Out of 56 patients who received ASV, 10 patients(18\%) had anaphylaxis . 3 patients developed AKI( acute kidney injury), 1 was conservatively managed and 2 were referred to GRH, Madurai for hemodialysis.Only 8 Patients needed surgical intervention in the form of I \& D and fasciotomy.

Table 6

\begin{tabular}{|l|c|c|c|}
\hline Description & \multicolumn{2}{|c|}{ Outcome of Snake bites } & No. of persons \\
\hline \multirow{3}{*}{ Outcome } & \multirow{3}{*}{ Discharge } & $\begin{array}{l}\text { Without surgical } \\
\text { intervention }\end{array}$ & 74 \\
\cline { 2 - 3 } & $\begin{array}{l}\text { With surgical } \\
\text { intervention }\end{array}$ & 8 \\
\cline { 2 - 3 } & Referral & 2 \\
\cline { 2 - 3 } & Death & 1 \\
\hline
\end{tabular}

\section{Discussion}

In India, approximately 1 person is affected by snake bite every ten seconds. 1 person dies of snake bite every 2 hrs.Nearly 4,00,000 people are bitten by snakes in a year. Among those 82,000 suffer envenomation and 11,000 die. Rural: Urban ratio is 9:1. Our Government is spending huge sum of money in procuring and upplying ASV. Gaurav et al study[1]which was done in western Maharastra, showed incidence of poisonous snake bite is $50.6 \%$ while night time snake bite was $72 \%$.So compared to this study, our study showed increased incidence of poisonous snake bite ( $80 \%$ vs 50.6\%), increase in daytime bite (54\% vs 27\%). Arshad et al study[2] done at Uttar Pradesh showed results of increased Elapidae bite (15.4\% vs $4.7 \%)$, increased incidence of night time bite $(55.1 \%$ vs $46 \%$ ) \& increased mortality ( $8 \%$ vs $1.1 \%)$. Harshavardhana et al study[4] done at KIMS, Bangalore revealed similar incidence of Viperidae bite (70\% vs $73 \%$ ) with mortality of $4 \%$ (vs $1.1 \%$ ).

Rekha et al study done at Kasturba medical college, Mangalore showed similar incidence of Viperidae bite $(73.2 \%$ vs $72 \%)$ but with increased incidence in night time bite $(48.1 \%$ vs $46 \%)$. The percentage of ASV usage was $69 \%$ (vs 65\%) with mortality of $3 \%$ (vs 1.1\%). The study done by Nagaraju et al \&Gopinath et al [3] conducted in Coimbatore \& Bangalore showed increased incidence of nocturnal snake bite ( $64 \%$ vs $46 \%$ ) with mortality of $10 \%$ (vs $1.1 \%$ ) 
So on comparison with other studies our study showed increased incidence of day time bite. More over incidence of Viperidae snake bite was found to be similar when compared with South Indian studies. Also mortality was low in our study (1\%). Prevention is always better than cure. Deaths due to snake bite can be prevented by following simple steps by public and/ or health care provider when they see snake bite.

1. When they are walking at night, they can wear hard soled footwear and make heavy stamping steps .Snakes will sense the vibrations and stay away from that way.

2. Carrying sticks to separate the bushes and piles of stones in order to give time for snakes to move away.

3. Rubbish should be kept away from houses because it may attract rats and in turn snakes.

4. Plants should be grown away from doors and windows, as this may help snakes to climb into the house.

5. In the hospital patient should be well hydrated so as to prevent renal injury.

6. Appropriate antibiotics definitely help in bringing down the local envenomation (i.e. Cellulitis)

7. Early institution of ASV helps in removing the circulating venom and curing the patient

8. Silent killer in snake bite is neurotoxicity. Early identification and treatment is important.

\section{References}

[1]. Bhalla G, Mhaskar D, Agarwal A. A study of clinical profile of snake bite at a tertiary care centre. Toxicol Int. 2014;21:203-8. [PMC free article] [PubMed]

[2]. Anjum Arshad, Husain M, Hanif SA, Ali SM, Beg M, et al. (2012) Epidemiological Profile of Snake Bite at Tertiary Care Hospital, North India. J Forensic Res 3:146. doi:10.4172/2157-7145.1000146

[3]. SURVEY ON PATTERN OF SNAKE BITE CASES ADMITTED IN SOUTH INDIAN TERTIARY CARE HOSPITALS Kiran Nagaraju , NagappanKannappan and K. Gopinath10.13040/IJPSR.0975-8232.6(10).4362-67

[4]. Snake Bite Induced Coagulopathy: A Study of Clinical Profile and Predictors of Poor OutcomeH S Harshavardhana ,ImtiazPasha, N C SrinivasaPrabhu, AmiraPreethika Ravi

[5]. International Journal of Scientific Study | April 2014 | Vol 2 | Issue 1

[6]. Jaggi OP. Medicine in India: Modern Period (History of Science, Philosophy and Culture in Indian Civilization, Vol. IX: Part 1) New Delhi: Oxford University Press; 2000.

[7]. Whitaker R, Captain A. Snakes of India: The Field Guide. Chennai: Draco Books; 2004.

[8]. Fayrer J. Destruction of life in India by poisonous snakes. Nature. 1882;27:205-208.

[9]. British Medical Journal. Snake bites. BMJ. 1892;2:620.

[10]. British Medical Journal. Indian sanitary reports. BMJ. 1927;1:538-539.

[11]. Swaroop S, Grab B. Snakebite mortality in the world. Bull World Health Organ. 1954;10(1):35-76. [PMC free article] [PubMed]

[12]. Government of India, Central Bureau of Health Intelligence. Health Status Indicators, National Health Profile 2007 and 2008 (Provisional): 3.1.2.9 State/UT wise Cases and Deaths Due to Snake Bite in India. 107-108. Available: http://cbhidghs.nic.in/writereaddata/mainlinkFile/Health Status Indicators.pdf (accessed 2011)

[13]. Hati AK, Mandal M, De MK, Mukherjee H, Hati RN. Epidemiology of snake bite in the district of Burdwan, West Bengal. J Indian Med Assoc. 1992;90(6):145-147. [PubMed]

[14]. Sharma SK, Chappuis F, Jha N, Bovier PA, Loutan L, et al. Impact of snake bites and determinants of fatal outcomes in southea stern Nepal. Am J Trop Med Hyg. 2004;71(2):234-238. [PubMed]

[15]. Kasturiratne A, Wickremasinghe AR, de Silva N, Gunawardena NK, Pathmeswaran A, et al. The Global Burden of Snakebite: A Literature Analysis and Modelling Based on Regional Estimates of Envenoming and Deaths. PLoS Med. 2008;5(11):e218. doi: 10.1371/journal.pmed.0050218. [PMC free article] [PubMed]

[16]. Chippaux JP. Snake-bites: appraisal of the global situation. Bull World Health Organ. 1998;76(5):515-524. [PMC free article] [PubMed] 